\title{
Bacterial Community Structure after Long-term Organic and Inorganic Fertilization Reveals Important Associations between Soil Nutrients and Specific Taxa Involved in Nutrient Transformations
}

\author{
Fang $\mathrm{Li}^{1,2+}$, Lin Chen ${ }^{2 \dagger}$, Jiabao Zhang ${ }^{1,2 *}$, Jun Yin ${ }^{1}$ and Shaomin Huang ${ }^{3}$ \\ ${ }^{1}$ Collaborative Innovation Center of Henan Grain Crops, Henan Agricultural University, Zhengzhou, China, ${ }^{2}$ State Key \\ Laboratory of Soil and Sustainable Agriculture, Institute of Soil Science, Chinese Academy of Sciences, Nanjing, China, \\ ${ }^{3}$ Institute of Plant Nutrition and Environmental Resources Science, Henan Academy of Agricultural Sciences, Zhengzhou, \\ China
}

\section{OPEN ACCESS}

Edited by:

Alexandre Jousset,

Utrecht University, Netherlands

Reviewed by:

Mark Radosevich,

University of Tennessee, USA

Thomas Pommier,

Institut National de la Recherche

Agronomique (INRA), France

*Correspondence:

Jiabao Zhang

jbzhang@issas.ac.cn

${ }^{\dagger}$ These authors have contributed equally to this work.

Specialty section: This article was submitted to

Terrestrial Microbiology, a section of the journal

Frontiers in Microbiology

Received: 26 October 2016 Accepted: 25 January 2017 Published: 09 February 2017

Citation:

Li F, Chen L, Zhang J, Yin J and Huang $S$ (2017) Bacterial Community Structure after Long-term Organic and Inorganic Fertilization Reveals Important Associations between Soil Nutrients and Specific Taxa Involved in Nutrient Transformations.

Front. Microbiol. 8:187.

doi: 10.3389/fmicb.2017.00187
Fertilization has a large impact on the soil microbial communities, which play pivotal roles in soil biogeochemical cycling and ecological processes. While the effects of changes in nutrient availability due to fertilization on the soil microbial communities have received considerable attention, specific microbial taxa strongly influenced by long-term organic and inorganic fertilization, their potential effects and associations with soil nutrients remain unclear. Here, we use deep $16 \mathrm{~S}$ amplicon sequencing to investigate bacterial community characteristics in a fluvo-aquic soil treated for 24 years with inorganic fertilizers and organics (manure and straw)-inorganic fertilizers, and uncover potential links between soil nutrient parameters and specific bacterial taxa. Our results showed that combined organic-inorganic fertilization increased soil organic carbon (SOC) and total nitrogen (TN) contents and altered bacterial community composition, while inorganic fertilization had little impact on soil nutrients and bacterial community composition. SOC and TN emerged as the major determinants of community composition. The abundances of specific taxa, especially Arenimonas, Gemmatimonas, and an unclassified member of Xanthomonadaceae, were substantially increased by organic-inorganic amendments rather than inorganic amendments only. A co-occurrence based network analysis demonstrated that SOC and TN had strong positive associations with some taxa (Gemmatimonas and the members of Acidobacteria subgroup 6, Myxococcales, Betaproteobacteria, and Bacteroidetes), and Gemmatimonas, Flavobacterium, and an unclassified member of Verrucomicrobia were identified as the keystone taxa. These specific taxa identified above are implicated in the decomposition of complex organic matters and soil carbon, nitrogen, and phosphorus transformations. The present work strengthens our current understanding of the soil microbial community structure and functions under long-term fertilization management and provides certain theoretical support for selection of rational fertilization strategies.

Keywords: long-term fertilization, soil bacteria, specific taxa, co-occurrence, nutrient transformations 


\section{INTRODUCTION}

Fertilization is an essential agricultural practice used primarily to increase nutrient availability to crop plants, with concomitant changes in the soil properties, and microbial communities (Marschner et al., 2003). These changes can in turn influence plant growth and health by increasing soil nutrient turnover, plant disease suppression, or disease incidence, etc., Increasing the sustainability of cropping systems involves the reduced inputs of agrochemical fertilizers and combined organic amendments to facilitate biological interactions for the provision of plant nutrients (Lazcano et al., 2013). Of particular importance are soil microbial processes given their pivotal roles in the dynamics of soil carbon (C) and nitrogen (N) (Wardle et al., 1999).

Certain bacterial taxa at high taxonomic levels (e.g., phylum or class) can display properties of ecological coherence since they respond predictably to environmental variables (Philippot et al., 2010; Cederlund et al., 2014). Earlier, Fierer et al. (2007) proposed that certain bacterial phyla could be differentiated into the ecologically relevant copiotrophic (or r-selected) and oligotrophic (or K-selected) categories based on their substrate preferences and life strategies. As thus, long-term fertilization can directionally change the abundance of certain bacterial phyla. But we still have no sufficient understanding of soil bacterial taxa at low taxonomic levels (e.g., genus or species) in response to long-term fertilization. Long-term repeated addition of organic $\mathrm{C}$ seems to select for certain microbial taxa at low taxonomic levels that feed primarily on organic substrates and proliferate greatly, resulting in the changes in microbial community composition and soil nutrient status (Marschner et al., 2003; Zhong et al., 2010; Cederlund et al., 2014). As a consequence, specific microbial taxa of which the abundances are substantially increased by longterm fertilization should show some degree of connections with soil nutrients. Moreover, these taxa show potential beneficial or detrimental effects on crop productivity and even agroecosystem stability (Francioli et al., 2016). The complex associations occur between microbial taxa in the context of exogenous organics decomposition and soil nutrient transformations (Chen et al., 2015a; Banerjee et al., 2016). Network analysis of taxon cooccurrence, as measured by correlations between abundances of microbial taxa, can help decipher complex microbial association patterns and the ecological rules guiding community assembly (Barberán et al., 2012). Network analysis cannot only reveal inter-taxa associations in the shared niche spaces but also link microbial taxa to environmental parameters (Fuhrman, 2009; Barberán et al., 2012).

Recent studies have used high-throughput sequencing to provide new insights into the soil microbial diversity and community composition under long-term organic and inorganic fertilization (e.g., Lentendu et al., 2014; Calleja-Cervantes et al., 2015; Zhou et al., 2015; Chen C. et al., 2016; Ding et al., 2016; Francioli et al., 2016). However, less is known about which microbial taxa at low taxonomic levels are strongly influenced by long-term organic and inorganic fertilization and how these taxa are linked to soil nutrient parameters. To address these knowledge gaps, we selected a long-term field experiment receiving 24 years of various types of inorganic fertilizers and combined organics-fertilizers, measured the related parameters of soil nutrients, and analyzed the soil bacterial community characteristics using deep sequencing of the 16S rRNA gene amplicons. We used recently developed differential abundance analysis and network analysis of cooccurrence to unravel the potential effects of specific bacterial taxa and their associations with soil nutrients. Specifically, we examined: (i) whether combined organic-inorganic fertilization causes more pronounced shifts in the soil bacterial community composition than inorganic fertilization alone, (ii) which specific taxa are substantially stimulated by long-term fertilization, and (iii) which soil parameters are well linked to these taxa. We hypothesized that: since $\mathrm{C}$ and $\mathrm{N}$ are the most important resources for bacterial growth, soil $\mathrm{C}$ and $\mathrm{N}$ would show great associations with some specific taxa of which the abundances are substantially increased by long-term fertilization.

\section{MATERIALS AND METHODS}

\section{Experimental Description and Sampling}

A long-term fertilizer field experiment was established in 1990 at Zhengzhou ( $\left.34^{\circ} 47^{\prime} \mathrm{N}, 113^{\circ} 40^{\prime} \mathrm{E}\right)$ of Henan Province, which is an important grain-producing area in China. The use of long-term field experiment has been approved by the legal entity "Henan Academy of Agricultural Sciences." This region undergoes a temperate monsoon climate, with an average annual precipitation, and temperature of $641 \mathrm{~mm}$ and $14.4^{\circ} \mathrm{C}$, respectively. The soil is a fluvo-aquic soil (clay $25 \%$, sand $27 \%$, an Inceptisol in the USDA soil taxonomy system) developing from alluvial sediments of the Yellow River (Chen L. et al., 2016). The experimental site included 33 plots (eleven treatments with three replicate plots of each, $10 \times 4 \mathrm{~m}$ for each plot). All plots were randomly arranged and cement plates were inserted between plots. Except fertilization, all other management practices (e.g., irrigation, tillage, and pesticides) were the same for all plots. We selected seven treatments with application of various types of organics and fertilizers: MNPK (organic manure plus NPK fertilizers), SNPK (maize straw plus NPK fertilizers), HNPK (high rate of $\mathrm{N}$ fertilizer, regular PK fertilizers), LNPK (low rate of $\mathrm{N}$ fertilizer, regular PK fertilizers), NP (NP fertilizers), NK (NK fertilizers), and CK (unfertilized control). Urea (N $45 \%)$, superphosphate $\left(\mathrm{P}_{2} \mathrm{O}_{5} 12 \%\right)$, and potash $\left(\mathrm{K}_{2} \mathrm{O} 60 \%\right)$ were applied as NPK fertilizers. The cropping system was wheat (Triticum aestivum L.) and maize (Zea mays L.) rotation. $165.0 \mathrm{~kg}$

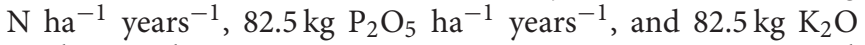
$\mathrm{ha}^{-1}$ years $^{-1}$ were given at wheat season, and $187.5 \mathrm{~kg} \mathrm{~N} \mathrm{ha}^{-1}$ years $^{-1}$, $93.8 \mathrm{~kg} \mathrm{P}_{2} \mathrm{O}_{5} \mathrm{ha}^{-1}$ years $^{-1}$, and $93.8 \mathrm{~kg} \mathrm{~K}_{2} \mathrm{O} \mathrm{ha}{ }^{-1}$ years $^{-1}$ at maize season (except LNPK with 110.0 and $125.0 \mathrm{~kg} \mathrm{~N}$ $\mathrm{ha}^{-1}$ years $^{-1}$ at wheat and maize seasons, respectively). Organic manure was cattle manure compost, on average, with $\mathrm{N} 12.7 \mathrm{~g}$ $\mathrm{kg}^{-1}$. Manure and straw were applied according to 7:3 of organic $\mathrm{N}$ :inorganic $\mathrm{N}$ ratio, i.e., 115.5 and $131.3 \mathrm{~kg}$ organic $\mathrm{N} \mathrm{ha}^{-1}$ years $^{-1}$ given at wheat and maize seasons, respectively, calculated from the $\mathrm{N}$ content of manure and straw.

The soils were sampled from the $0-20 \mathrm{~cm}$ plow layer in October 2014 after the harvest of maize. Six soil cores $(5 \mathrm{~cm}$ diameter, $20 \mathrm{~cm}$ depth) were randomly collected from each 
replicate plot and pooled into one composite sample. After visible stones and plant residues were removed, soil was homogenized and passed through a $2 \mathrm{~mm}$ mesh. All samples were divided into three parts, one portion was air-dried to determine the general soil properties, one was stored at $4^{\circ} \mathrm{C}$ to measure the potential activities of $\mathrm{C}, \mathrm{N}$ and $\mathrm{P}$-acquiring enzymes, and one at $-20^{\circ} \mathrm{C}$ for molecular analyses.

\section{Soil Biochemical Characterization}

Soil $\mathrm{pH}$ was measured in a 1:2.5 soil solution $(0.01 \mathrm{M} \mathrm{CaCl} 2)$ with a Starter-2100 $\mathrm{pH}$ probe (Ohaus, Brooklyn, NY, USA). Soil organic $\mathrm{C}(\mathrm{SOC})$ and total $\mathrm{N}(\mathrm{TN})$ contents were determined by the $\mathrm{K}_{2} \mathrm{Cr}_{2} \mathrm{O}_{7}$ digestion and Kjeldahl determination methods, respectively. Available $\mathrm{P}$ (AP) content was determined by $\mathrm{NaHCO}_{3}$ extraction-colorimetry and available $\mathrm{K}(\mathrm{AK})$ content by $\mathrm{CH}_{3} \mathrm{COONH}_{4}$ extraction-flame photometry. Invertase activity (ITA) was analyzed using a 3,5-dinitrosalicylic acid method (Bandick and Dick, 1999). Urease activity (UEA) and alkine phosphatase activity (PTA) were quantified by measuring the breakdown rate of substrates urea and $p$-nitrophenyl-phosphate, respectively (Tabatabai, 1994).

\section{Preparation of Amplicon Library and Sequencing}

The total DNA was extracted from $0.50 \mathrm{~g}$ of fresh soils using the FastDNA Spin Kit for Soil (MP Biomedicals, Santa Ana, CA, USA), following the kit's directions. The isolated DNA was dissolved in $50 \mu \mathrm{l}$ of TE buffer. DNA quality and concentrations were estimated based on spectrometry absorbance at wavelengths of 230, 260, and $280 \mathrm{~nm}$ detected by a NanoDrop ND-1000 spectrophotometer (NanoDrop Technologies, Wilmington, DE, USA). DNA was frozen at $-80^{\circ} \mathrm{C}$ for downstream assays.

PCR amplification was carried out using primers F515 (5'-GTGCCAGCMGCCGCGGTAA-3')/R806 (5'-GGACTACVS GGGTATCTAAT- $3^{\prime}$ ) designed against the V4 region of the bacterial 16S rRNA gene (Caporaso et al., 2011). The reverse primer is barcoded with an 8-base sample-specific sequence to facilitate multiplexing of a sample set, and both primers contain sequencer adapter regions. The reaction mix was done in a volume of $50 \mu \mathrm{l}$ consisting of $27 \mu \mathrm{l}$ of $\mathrm{dd}_{2} \mathrm{O}, 2 \mu \mathrm{l}(5 \mu \mathrm{M})$ of each forward/reverse primer, $2.5 \mu \mathrm{l}(10 \mathrm{ng})$ of template DNA, $5 \mu \mathrm{l}(2.5 \mathrm{mM})$ of deoxynucleoside triphosphates, $10 \mu \mathrm{l}$ of 5 $\times$ Fastpfu buffer, $0.5 \mu \mathrm{l}$ of bovine serum albumin, and $1 \mu \mathrm{l}$ of TransStart Fastpfu polymerase (TransGen, Beijing, China). Thirty thermal cycles $\left(15 \mathrm{~s}\right.$ at $94^{\circ} \mathrm{C}, 15 \mathrm{~s}$ at $55^{\circ} \mathrm{C}$, and $30 \mathrm{~s}$ at $72^{\circ} \mathrm{C}$ ) were conducted with a final extension at $72^{\circ} \mathrm{C}$ for $10 \mathrm{~min}$. The quality of reaction products were verified on a $1 \%$ agarose gel.

PCR products were purified using a PCR Clean-up Purification Kit (MP Biomedicals), and quantified using a Qubit 2.0 fluorimeter (Invitrogen, Carlsbad, CA, USA). The purified amplicons were pooled in equimolar concentrations and loaded on a MiSeq Reagent Kit V2, and dual index sequencing of paired-end $250 \mathrm{bp}$ was run on an Illumina MiSeq instrument (Illumina, San Diego, CA, USA). The sequence data were submitted to NCBI Sequence Read Archive (https://www.ncbi. nlm.nih.gov/sra/) with accession number SRP094809.

\section{Community Bioinformatics and Statistics}

The clustering of operational taxonomic unit (OTU) was conducted using the UPARSE pipeline (Edgar, 2013), based on the following workflow: (i) quality filtering sequences using a "maxee" (i.e., maximum per sequence expected error frequency) value of 1 and trimmed to a consistent length; (ii) dereplicating identical sequences and removing singleton reads; (iii) building a de novo dataset of $>97 \%$ similar sequence clusters and simultaneously removing chimera on this non-redundant dataset, using self-dataset and RDP gold sequence (Cole et al., 2014) as reference; (iv) generating OTU abundance table by mapping the total reads to representative sequence. Taxonomic annotation was assigned to each OTU representative sequence by UCLUST (Edgar, 2010) in QIIME v.1.9.0 (Caporaso et al., 2010) against the Greengenes 13_8 database. All sequences unassigned and assigned to archaea were removed.

The remaining sequences of all samples were rarefied to the same sequencing depth (25,223 sequences per sample). Principal coordinate analysis (PCoA) of the weighted and unweighted UniFrac (Lozupone and Knight, 2005) distances was calculated in the R package "ape." Canonical analysis of principal coordinates (CAP) was performed in the R package "vegan." When specifying CAP models, we constrained the analysis to edaphic factors while conditioning on all other factors. Effect significance of factors was calculated by running the vegan's permutest function over the CAP model using a maximum of 500 permutations. Mantel tests revealed the correlations between soil biochemical properties and bacterial community composition.

We used the R package "DESeq2" to calculate the OTUs differential abundance (i.e., $\log _{2}$-fold change in relative abundance of each OTU) for each fertilizer regime as compared to unfertilized control. Differential abundance analysis was conducted by fitting a generalized linear model with a negative binomial distribution to normalized value for each OTU and testing for differential abundance using a Wald test (Love et al., 2014). We adjusted $P$-values for multiple testing using the procedure of Benjamini and Hochberg (1995), and selected a false discovery rate (FDR) of $10 \%$ to denote statistical significance (Love et al., 2014; Whitman et al., 2016). Enriched and depleted OTUs were defined as OTUs with absolute differential abundance $>1.0$ and adjusted $P<0.1$.

\section{Network Analysis}

Network analysis was conducted on bacterial OTUs and soil properties using the maximal information coefficient (MIC) in MINE software (Reshef et al., 2011). The MIC is a highly useful score that reveals the strength of linear and non-linear associations among variables (Reshef et al., 2011). To minimize pairwise comparisons and reduce network complexity, only OTUs with large differential abundance (adjusted $P<0.05$ ) in at least one fertilizer regime were selected for network analysis. After the pairwise comparisons in MINE software, top 10,000 interactions were selected. The resulting 241 OTUs with strong positive $(r>0.8)$, strong negative $(r<-0.8)$ and strong non-linear $\left(\mathrm{MIC}-\rho^{2}>0.8\right)$ relationships were used for network construction in Cytoscape v.3.2.1 (Shannon et al., 2003). Network topological characteristics were calculated 
using NetworkAnalyzer tool in Cytoscape. Modular structure of highly interconnected nodes was analyzed using the MCODE application with default parameters. OTUs with maximum betweenness centrality scores were considered as keystone species (Vick-Majors et al., 2014; Banerjee et al., 2016).

\section{RESULTS}

\section{Soil Biochemical Properties}

Soil $\mathrm{pH}$ and AP content showed no statistical differences between treatments. Inorganic fertilization (i.e., NK, NP, LNPK, and HNPK treatments) had little impact on SOC and TN contents. NPK fertilizers with combined application of manure (MNPK) and straw (SNPK) significantly increased SOC content by 52.3 and $47.1 \%$, respectively, and significantly increased TN content by 36.4 and $49.1 \%$, respectively. AK content was significantly enhanced by SNPK (56.6\%), but little affected by other treatments (Table 1). Urease activity (UEA) was significantly improved by MNPK, but little affected by other treatments. Phosphatase activity (PTA) and invertase activity (ITA) showed 2.3 and 5.3fold increases in SNPK, respectively, as compared to unfertilized control (Table 1).

\section{Relative Abundance of Major Phyla and Families}

Acidobacteria (16-21\%), Bacteroidetes (11-20\%), and Proteobacteria (23-30\%) were the dominant phyla across treatments. Among the classes of Proteobacteria, Betaproteobacteria (8-14\%) had the highest relative abundance (Figure 1A). MNPK had higher relative abundance of Betaproteobacteria, and SNPK had higher Bacteroidetes than other treatments. Acidobacteria in HNPK and MNPK were more abundant (Figure 1A). Top 15 families with average relative abundance of $>3.5 \%$ were analyzed (Figure 1B). MNPK led to a remarkable increase (4.4-fold increase) in the relative abundance of Xanthomonadaceae, but significant decrease in the relative abundances of Planctomycetaceae, Gaiellaceae, and Nitrospiraceae. Similarly, the relative abundances of Planctomycetaceae, Gaiellaceae, and Nitrospiraceae (especially Gaiellaceae, $P<0.01$ ) were largely decreased by SNPK. The significantly increased abundances of Chitinophagaceae and Sphingomonadaceae occurred in HNPK (Figure 1B).

\section{Community Structure, Variation, and Determinants}

Principal coordinate analysis (PCoA) with weighted and unweighted UniFrac distance matrixes demonstrated the distinct community separation of MNPK and SNPK from other treatments, along the first principle coordinates (Figures 2A,B). The UniFrac distance is based on taxonomic relatedness, where weighted UniFrac takes abundance of taxa into consideration whereas unweighted UniFrac does not and is thus more sensitive to rare taxa. The moderate community separation between inorganic fertilization and non-fertilization (Figure 2B) indicates that the application of inorganic fertilizers has a certain influence on rare bacterial species. We used CAP to quantify the impacts of edaphic factors (i.e., $\mathrm{pH}$, SOC,
TN, AP, and AK) on bacterial community composition. The five constrained factors substantially contributed to bacterial community variation $(49.31 \%$ of variation, $P=$ 0.006 , weighted UniFrac; $30.93 \%$ of variation, $P=0.002$, unweighted UniFrac), and SOC and TN were the determinants among these factors (Figures 2C,D). Mantel test revealed great correlations of SOC $(P \leq 0.002)$ and $\mathrm{TN}(P=0.001)$ with bacterial community composition (Table S1). SOC and TN also had significant correlations with the relative abundance of some major phyla and families, e.g., positive relationships with Betaproteobacteria and Xanthomonadaceae, and negative relationships with Planctomycetes, Alphaproteobacteria, and Nitrospiraceae (Table S2). These results suggest that the soil bacterial community composition under long-term fertilization was mainly driven by SOC and TN contents.

\section{Enriched and Depleted OTUs by Long-term Fertilization}

We conducted differential abundance analysis to identify OTUs that were strongly influenced by different fertilization regimes. Using OTU abundance from unfertilized soil as control and an adjusted $P$-value cutoff of 0.1 , "enriched OTUs (eOTUs)" and "depleted OTUs (dOTUs)" specifically represent OTUs that increase and decrease significantly in relative abundance by more than doubling in response to long-term fertilization, respectively. There were 163 and 108 eOTUs (primarily the identifiable eOTUs from the phyla Bacteroidetes, Betaproteobacteria, Gammaproteobacteria, and Acidobacteria, Table 2), and 248 and 126 dOTUs (primarily phyla Acidobacteria, Alphaproteobacteria, Actinobacteria, and Bacteroidetes, Table 2) in MNPK and SNPK, respectively (Figures 3A,B; Dataset S1). Among top 10 most influential OTUs in MNPK and SNPK, eOTUs were mainly identified as Arenimonas, Gemmatimonas, and several unclassified members of Xanthomonadaceae, and dOTUs mainly as Gaiella, Nitrospira, Sphingomonas, and several unclassified members of Sphingomonadaceae (Table 2). There were much fewer OTUs enriched and depleted by inorganic fertilization compared to combined organic-inorganic fertilization, with the notable exception of HNPK in which 123 dOTUs (primarily phyla Bacteroidetes, Actinobacteria, and Acidobacteria, Table 2) were comparable to SNPK (Figures 3C-F; Dataset S1).

\section{Network Associations among OTUs and Soil Properties}

The network comprised 874 significant associations (edges) of 245 nodes, with an average clustering coefficient of 0.32 and overall diameter of 11 edges (Table S3). The network exhibited an average number of neighbors of 7.14 and characteristic path length of 3.99 (Table S3). Network edges were predominantly composed of strong positive associations, and the dominant identifiable OTUs belonged to Acidobacteria, Bacteroidetes, and Gammaproteobacteria (Figure 4A). SOC showed a strong positive association with one Acidobacteria subgroup 6 (Gp6) member (Figure 4B; Dataset S2). TN showed strong positive associations with Gemmatimonas, one Acidobacteria Gp6 member, one Myxococcales member and two members within 
TABLE 1 | Soil biochemical properties among different fertilization regimes.

\begin{tabular}{|c|c|c|c|c|c|c|c|c|}
\hline & $\mathrm{pH}$ & $\operatorname{soc}\left(\mathrm{mg} \mathrm{g}^{-1}\right)$ & $\mathrm{TN}\left(\mathrm{mg} \mathrm{g}^{-1}\right)$ & $\mathrm{AP}\left(\mu \mathrm{g} \mathrm{g}^{-1}\right)$ & $A K\left(\mu g g^{-1}\right)$ & PTA $\left(\mu g_{g^{-1}} h^{-1}\right)$ & UEA $\left(\mu g_{g^{-1}} h^{-1}\right)$ & ITA (mg g $\left.g^{-1} h^{-1}\right)$ \\
\hline CK & $8.11 \pm 0.08 a$ & $6.16 \pm 0.45 b$ & $0.55 \pm 0.05 c$ & $8.27 \pm 0.58 a$ & $96.70 \pm 16.56 \mathrm{bc}$ & $1.76 \pm 0.28 b$ & $16.97 \pm 3.05 b$ & $0.90 \pm 0.31 b$ \\
\hline NK & $8.27 \pm 0.04 a$ & $5.99 \pm 0.67 b$ & $0.61 \pm 0.05 b c$ & $18.61 \pm 19.33 a$ & $135.66 \pm 7.24 a b c$ & $2.02 \pm 0.21 b$ & $20.03 \pm 2.06 a b$ & $2.22 \pm 1.18 b$ \\
\hline NP & $8.12 \pm 0.01 a$ & $7.59 \pm 0.85 a b$ & $0.72 \pm 0.03 a b c$ & $11.54 \pm 2.80 a$ & $92.83 \pm 12.41 \mathrm{c}$ & $1.43 \pm 0.41 b$ & $20.25 \pm 3.11 a b$ & $1.75 \pm 0.90 b$ \\
\hline LNPK & $8.18 \pm 0.08 a$ & $7.88 \pm 0.46 a b$ & $0.57 \pm 0.04 c$ & $11.33 \pm 2.57 a$ & $144.77 \pm 21.95 \mathrm{ab}$ & $1.68 \pm 1.05 b$ & $17.01 \pm 2.15 b$ & $2.26 \pm 0.88 b$ \\
\hline HNPK & $7.82 \pm 0.34 a$ & $8.10 \pm 0.77 a b$ & $0.64 \pm 0.05 a b c$ & $10.55 \pm 5.38 a$ & $114.63 \pm 2.70 a b c$ & $2.02 \pm 0.21 b$ & $22.08 \pm 1.31 \mathrm{ab}$ & $2.67 \pm 0.58 a b$ \\
\hline MNPK & $8.08 \pm 0.00 a$ & $9.38 \pm 1.03 a$ & $0.75 \pm 0.05 a b$ & $12.29 \pm 2.24 a$ & $123.42 \pm 31.26 a b c$ & $3.39 \pm 0.99 a b$ & $23.94 \pm 1.84 a$ & $2.53 \pm 0.86 b$ \\
\hline SNPK & $7.95 \pm 0.27 a$ & $9.06 \pm 1.69 a$ & $0.82 \pm 0.14 a$ & $8.44 \pm 0.82 a$ & $151.46 \pm 14.17 a$ & $4.10 \pm 1.20 \mathrm{a}$ & $22.82 \pm 0.40 a b$ & $4.81 \pm 0.25 a$ \\
\hline
\end{tabular}

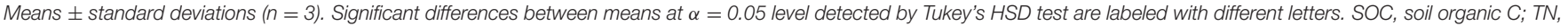

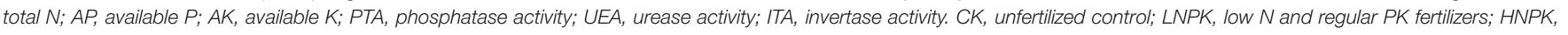
high $N$ and regular PK fertilizers; MNPK, organic manure plus NPK fertilizers; SNPK, maize straw plus NPK fertilizers.

A

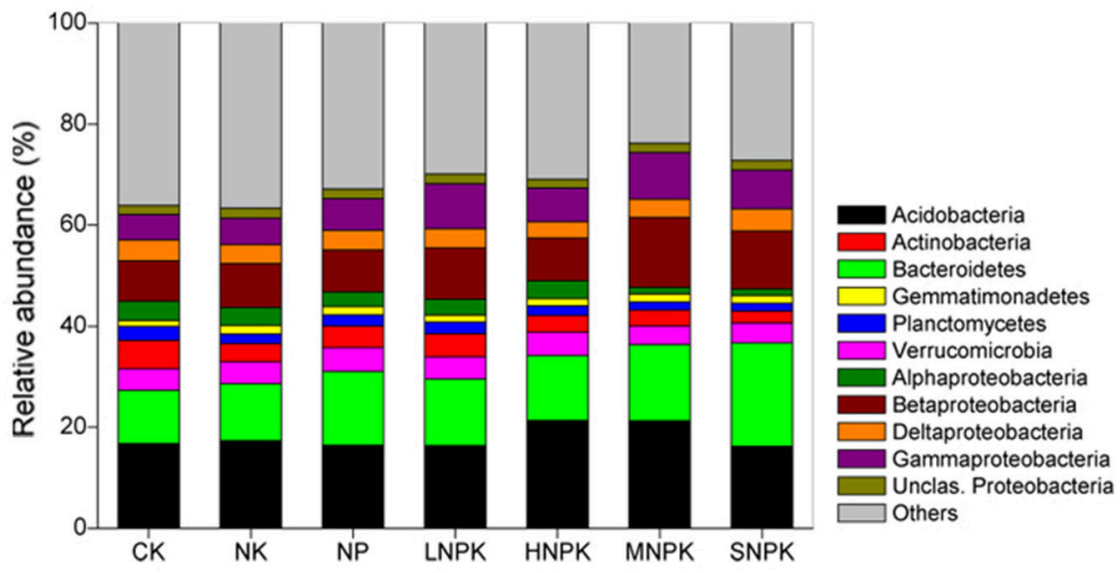

B

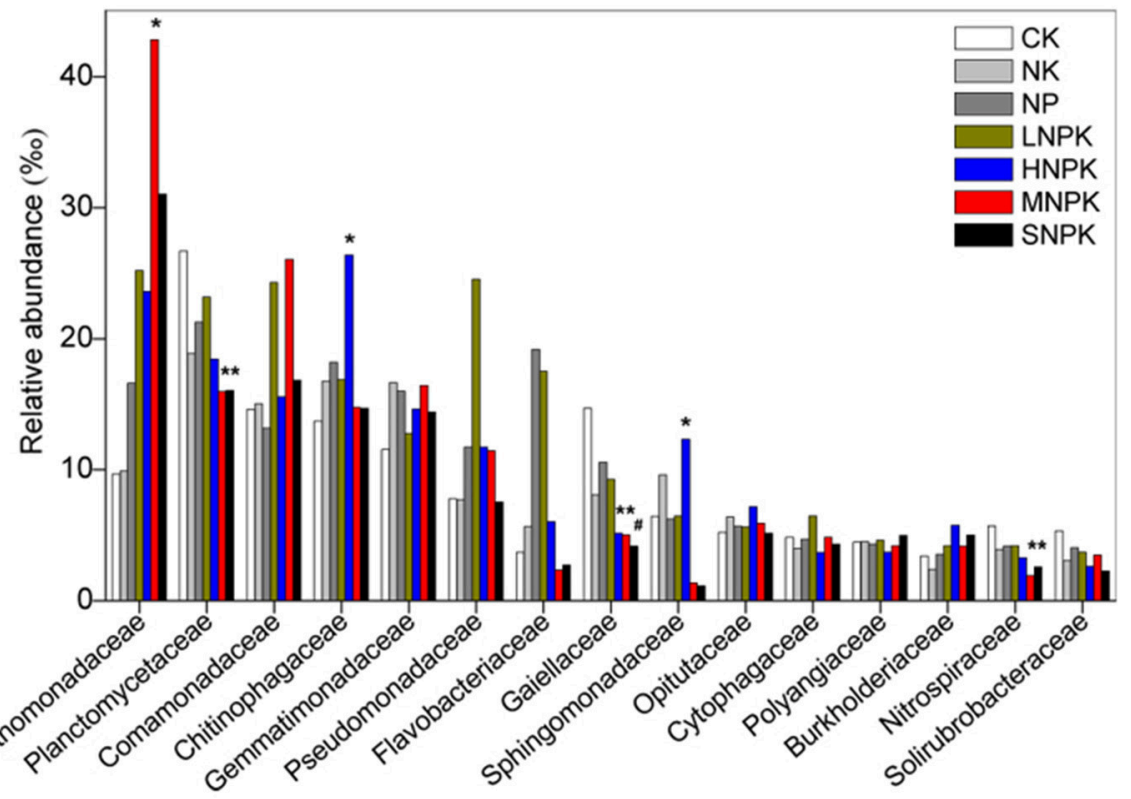

FIGURE 1 | Stacked and unstacked histograms showing the relative abundance of (A) major bacterial phyla and dominant classes of Proteobacteria and (B) 15 most abundant bacterial families, respectively, in treatments CK (unfertilized control), NK, NP, LNPK (low rate of N, regular PK), HNPK (high rate of N, regular PK), MNPK (manure plus NPK) and SNPK (straw plus NPK). Each stripe represents the mean of three replicates. * and \# mark significant differences at $P<0.05$ and 0.01 , respectively. 

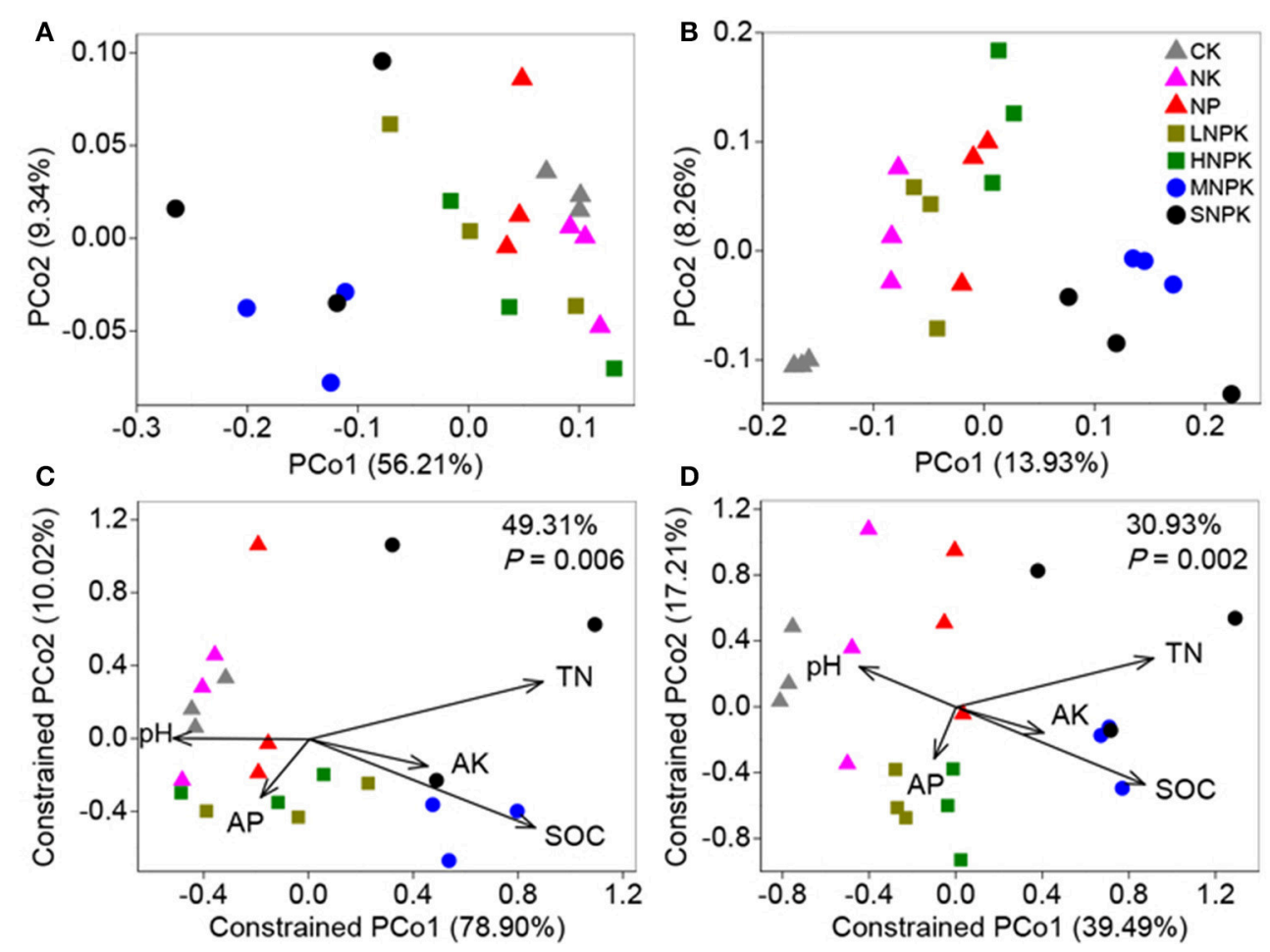

FIGURE 2 | Bacterial community variation between all samples from treatments CK (unfertilized control), NK, NP, LNPK (low rate of N, regular PK), HNPK (high rate of N, regular PK), MNPK (manure plus NPK) and SNPK (straw plus NPK). (A,B) Principal coordinate analysis plots of OTU-based weighted (A) and unweighted (B) UniFrac distances between samples; (C,D) Canonical analysis of principal coordinates (CAP) of weighted (C) and unweighted (D) UniFrac distances quantifying the impacts of edaphic factors on bacterial community structure. CAP was constrained to the factors pH, SOC, TN, AP, and AK while conditioning on all other factors.

Betaproteobacteria and Bacteroidetes (Figure 4C; Dataset S2). Based on betweenness centrality scores, the OTUs identified as keystone taxa were Gemmatimonas, Flavobacterium and one Subdivision3 member within Verrucomicrobia (Dataset S2).

\section{DISCUSSION}

We used deep $16 \mathrm{~S}$ amplicon sequencing to investigate the bacterial community characteristics in the fluvo-aquic soil treated for 24 years with various types of inorganic fertilizers and combined organic amendments and inorganic fertilizers. Bacterial communities across all treatments were dominated by the phyla Acidobacteria, Bacteroidetes, and Proteobacteria (Figure 1), which roughly correspond to previous studies in agricultural soils (Zhong et al., 2015; Zhou et al., 2015; Ding et al., 2016). As anticipated, combined organic-inorganic fertilization dramatically changed the soil bacterial community composition, but inorganic fertilization alone had little impact on bacterial community composition (Figure 2). Similar results were reported previously, based on the phospholipid fatty acid analysis (Lazcano et al., 2013; Williams et al., 2013). Our study supports the principle that the bacterial community in cropland soils is primarily influenced by organic component of agricultural fertilization. Bacterial growth is often limited by $\mathrm{C}$ availability, even in soils with high C:N ratio (Demoling et al., 2007). Fastgrowing copiotrophic bacteria proliferate soon after the supply of readily available $\mathrm{C}$ substrates to the soil and decrease later, and the growth of slow-growing oligotrophic bacteria recovers as substrate $\mathrm{C}$ availability declines over time. Thus, the succession of bacterial community occurs during repeated addition of organic matters. It was observed even that bacterial growth and community structure were changed in a short time period by a small fraction of organic component in the total amount of fertilizers applied (Lazcano et al., 2013).

There is the possibility that allochthonous inputs of bacterial taxa from organic amendments contribute to the alteration in the soil bacterial community composition. However, some studies have revealed the negligible effects of introduced bacteria from manure amendment on the soil bacterial community (Chu et al., 2007; Sun et al., 2015). The microbes in manure which are well adapted to the gut environments are less competitive than indigenous microbes in soils (Sun et al., 2015). Bacteroidetes is one of the most abundant bacterial phyla in cattle manure (Shanks et al., 2011), but we did not find large changes in the relative abundance of Bacteroidetes between treatments with and without cattle manure amendment (Figure 1). In addition, bacterial responses to manure amendment differ somewhat from straw amendment. We observed increased abundance of Acidobacteria but decreased abundance of Bacteroidetes 


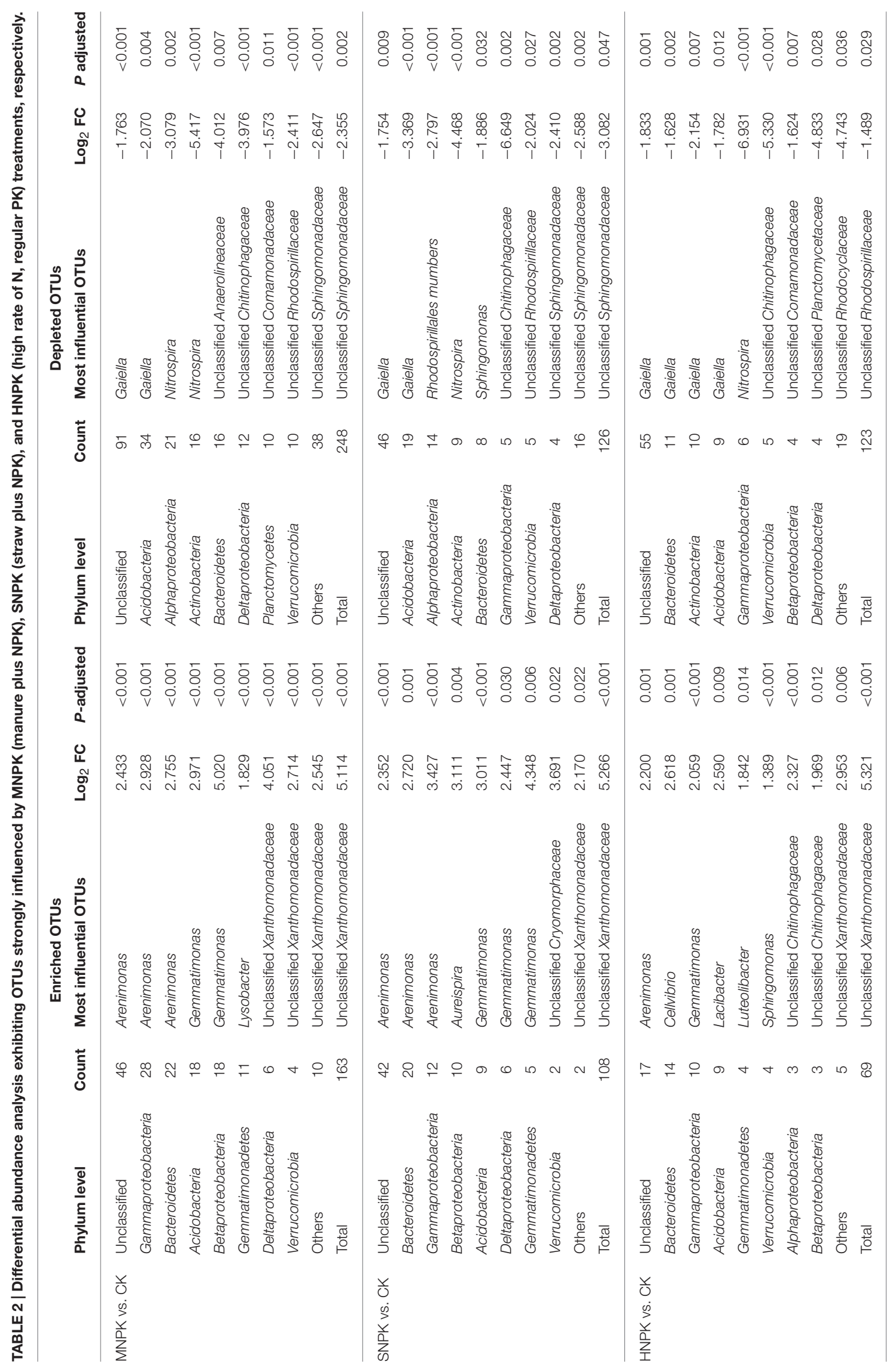




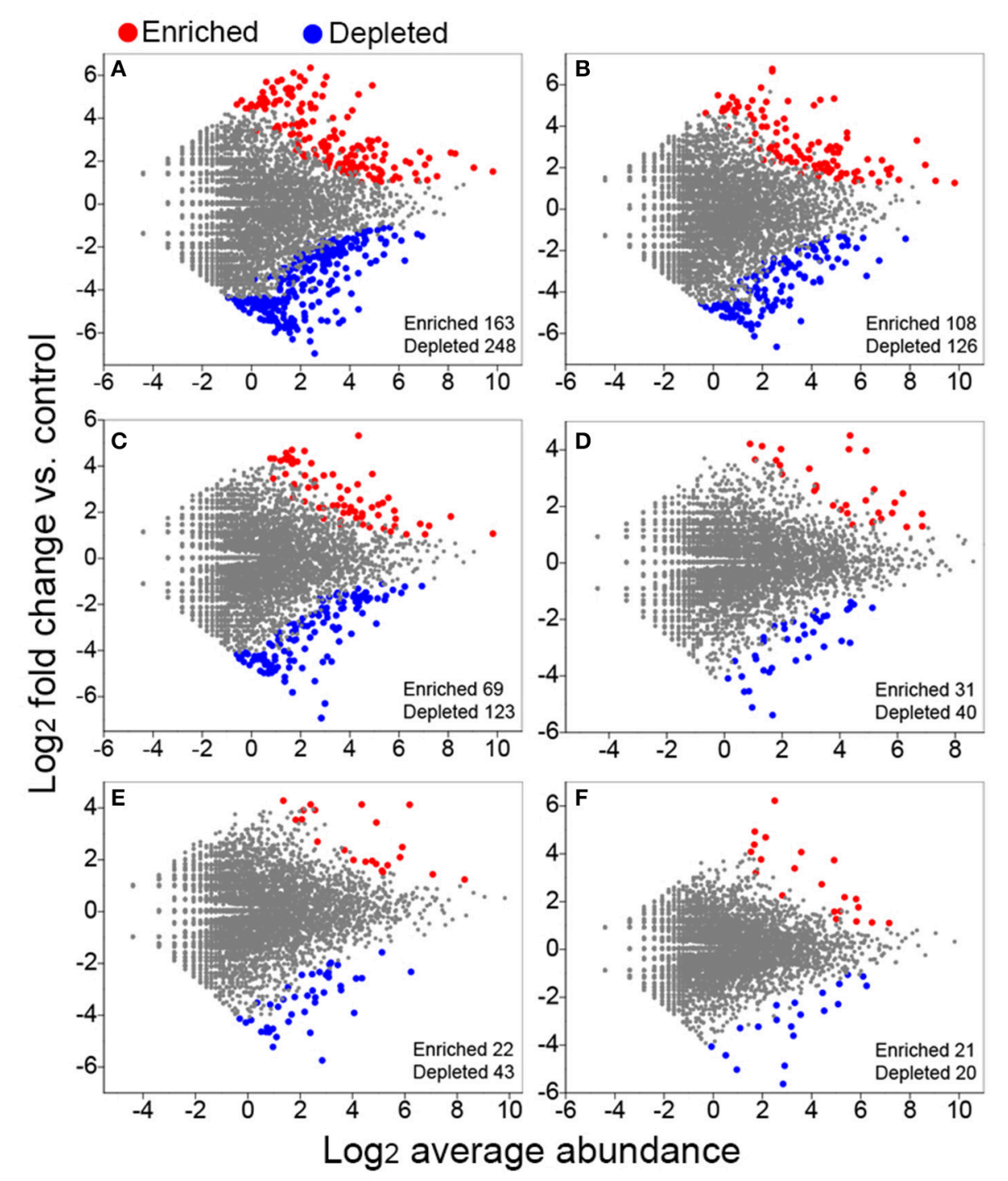

FIGURE 3 | Volcano plots illustrating OTUs significantly enriched (red) and depleted (blue) by long-term fertilization compared with unfertilized control as determined by differential abundance analysis. Each point represents an individual OTU, and the $Y$ axis indicates the abundance fold change vs. unfertilized control. (A) MNPK (manure plus NPK) vs. control; (B) SNPK (straw plus NPK) vs. control; (C) HNPK (high rate of N, regular PK) vs. control; (D) LNPK (Iow rate of N, regular PK) vs. control;(E) NP vs. control; (F) NK vs. control.

in manure plus NPK treatment (MNPK) compared to straw plus NPK treatment (SNPK), and bacterial phylotypes were more enriched and depleted by MNPK compared to SNPK (Figures 1, 3). The possible explanation is that organic manure contains more labile organic $\mathrm{C}$ and lower $\mathrm{C}: \mathrm{N}$ ratio than crop straw. The type of $\mathrm{C}$ input has been found to be a main factor determining the shifts in the soil bacterial community structure (Eilers et al., 2010; Shi et al., 2011; Pascault et al., 2013).

The results of ordination and correlation analyses between bacterial community characteristics and soil properties reveal that soil $\mathrm{C}$ and $\mathrm{N}$ contents are the main drivers for bacterial community composition under long-term fertilization (Figure 2; Tables S1, S2). When soil was amended with exogenous organics and fertilizers, certain microbial taxa are able to decompose organics and simultaneously acquire $\mathrm{N}$ from fertilizers to grow and reproduce rapidly under appropriate C:N stoichiometric ratios. In this situation, exogenous organics, and microbial metabolites are continuously decomposed and transformed, resulting in the changes in soil $\mathrm{C}$ and $\mathrm{N}$ contents over a long period of time. On the other hand, manure and straw amendments can stimulate the activity of some oligotrophs to mineralize recalcitrant soil organic matter (SOM) by using fresh organic matter as energy source, and cause a short-term change in SOM turnover, aka priming effect (Blagodatskaya and Kuzyakov, 2008). Therefore, soil C and N contents have necessary links with bacterial community composition 


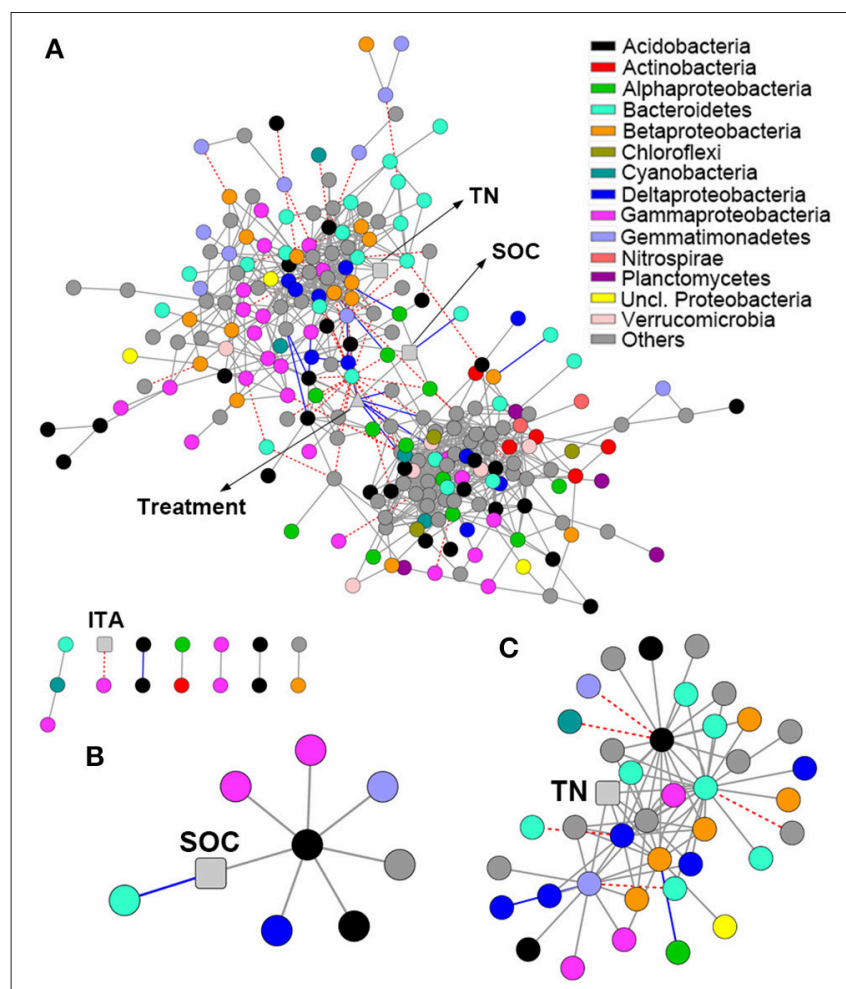

FIGURE 4 | Network analysis revealing the associations among bacterial OTUs and soil properties. Gray solid line, blue solid line and red dash line represent strong positive linear $(r>0.8)$, strong negative linear $(r<$ -0.8) and strong nonlinear (MIC- $\rho^{2}>0.8$ ) relationships, respectively. Colored nodes signify corresponding OTUs assigned to major phyla and classes. Soil properties are indicated with round rectangle, and treatment with triangle. SOC, soil organic C; TN, total N; ITA, invertase activity. (A) Network co-occurrences of OTUs substantially enriched by long-term fertilization; (B,C), Subnetworks for the associations of SOC (B) and TN (C).

under long-term fertilization. The importance of soil $\mathrm{C}$ and $\mathrm{N}$ contents in shaping bacterial community composition was also reported previously (Helgason et al., 2010; Shen et al., 2010; Sul et al., 2013; Liu et al., 2014; Chen C. et al., 2016).

We conducted differential abundance analysis to pick out OTUs that were responsible for the observed community differences between the fertilized and unfertilized soils. The OTUs primarily from Bacteroidetes, Betaproteobacteria, Gammaproteobacteria, and Acidobacteria were significantly enriched by long-term fertilization, especially combined organic-inorganic fertilization (Table 2). Bacteroidetes, Betaproteobacteria, and Gammaproteobacteria as copiotrophs thrive under conditions where substrate availability is high (Fierer et al., 2007; Eilers et al., 2010; Nemergut et al., 2010; Chen et al., 2015b). Despite there are many oligotrophic members within the Acidobacteria phylum (Nemergut et al., 2010; Pascault et al., 2013), some Acidobacteria members were depleted but some were enriched by combined organic-inorganic fertilization (Table 2). Our results are in agreement with previous findings that some Acidobacteria members (e.g., subgroups 1 and 7) were very few but some (e.g., subgroups 4 and 6) were abundant in soils with high content of organic C (Liu et al., 2014). We analyzed top 10 most influential OTUs at the genus level, and found that most enriched OTUs by manure and straw amendments were Arenimonas, Gemmatimonas, and several unclassified members of the Xanthomonadaceae family (Table 2). The Arenimonas species have catalytic activities of acid and alkaline phosphatase, esterase, esterase lipase, lipase, arylamidase, etc., (Jin et al., 2012; Huy et al., 2013; Makk et al., 2015). According to genome sequencing information, Arenimonas is capable of metabolizing casein, gelatin, $\beta$-hydroxybutyric acid, tyrosine, L-alaninamide, L-glutamic acid, and glycyl-L-glutamic acid (Chen et al., 2015c). Gemmatimonas is able to modulate $\mathrm{C}$ and $\mathrm{N}$ intakes according to their metabolic needs under various conditions (Carbonetto et al., 2014). Gemmatimonas shows high abundance in soils added with pyrogenic organic matters (Xu et al., 2014; Whitman et al., 2016), indicating that Gemmatimonas is likely to decompose polyaromatic C. Gemmatimonas was reported as a polyphosphate-accumulating bacterium (Zhang et al., 2003), and could be stimulated by increased input of $\mathrm{P}$ fertilizer in agricultural management (Su et al., 2015). These findings are supported by our results that some Gemmatimonas phylotypes (e.g., OTU_289 and OTU_78; dataset S1) were enriched by NP treatment rather than NK treatment. Moreover, Gemmatimonas was found at a high abundance in the rhizosphere of healthy wheat plants (Yin et al., 2013), indicating that Gemmatimonas may help suppress diseases and promote plant growth. The Xanthomonadaceae members within Gammaproteobacteria are known hydrocarbon decomposers, and they have also been shown to obtain $\mathrm{C}$ from co-occurring microorganisms (Lueders et al., 2006). Moreover, the Xanthomonadaceae family has been previously described as being dominant in the decomposing process of wood materials (Folman et al., 2008; Hervé et al., 2014). In summary, specific bacterial taxa substantially enriched by combined organic-inorganic fertilization play important roles in organics decomposition and soil $\mathrm{C}, \mathrm{N}$, and $\mathrm{P}$ transformations.

Since $\mathrm{C}$ and $\mathrm{N}$ are the most important resources for bacterial growth, soil $\mathrm{C}$, and $\mathrm{N}$ would show great associations with some specific taxa significantly enriched by long-term fertilization. Our hypothesis is confirmed by a co-occurrence based network analysis that revealed strong positive associations of SOC and TN with some taxa (e.g., Gemmatimonas and the members of Acidobacteria subgroup 6 and Myxococcales) (Figure 4; Dataset S2). The roles of Gemmatimonas involved in soil nutrient transformations are discussed above. Some subgroups of Acidobacteria are abundant in soils with high SOC level (Liu et al., 2014), and their ability to decompose organic matters has been reported previously (Rawat et al., 2012; Tveit et al., 2014). Myxococcales members act as the active micropredators in the soil microbial food web and play important roles in soil C sequestration (Lueders et al., 2006; Zhou et al., 2014). Betweenness centrality score discerns the modules that are most important in maintaining connectivity in an ecological network, and thus can be used for identification of keystone species (Vick-Majors et al., 2014). Based on betweenness centrality score, Gemmatimonas, Flavobacterium, and an unclassified Subdivision3 member of Verrucomicrobia were identified as the keystone taxa. Flavobacterium is responsible for heterotrophic 
denitrification (Wang et al., 2016). Verrucomicrobia members have been previously reported as degraders of recalcitrant organic matters (Fierer et al., 2013).

In terms of organic and inorganic fertilization alone, the former usually produces lower crop yield (Seufert et al., 2012), but the latter causes more environmental problems (Davidson, 2009). The integrated strategies of organic amendments and inorganic fertilizers are evaluated as a most effective way to enhance crop productivity and increase SOM level in China (Gong et al., 2009; Liu et al., 2010; Wei et al., 2016). Our longterm observation data also shows comparable and even higher yields of maize and wheat under combined organic-inorganic fertilization compared to inorganic fertilization (Figure S1). Meanwhile, combined organic-inorganic fertilization increased the potential activities of soil invertase, urease, and alkaline phosphatase, which are three typical microbial exoenzymes involved in $\mathrm{C}, \mathrm{N}$, and $\mathrm{P}$ mineralization. More importantly, compared to inorganic fertilization, combined organic-inorganic fertilization enriched more amounts of specific bacterial taxa. These taxa are implicated in the decomposition of complex organic matters and soil nutrient transformations, and are thus beneficial for plant growth by improving nutrient availability.

\section{REFERENCES}

Bandick, A. K., and Dick, R. P. (1999). Field management effects on soil enzyme activities. Soil Biol. Biochem. 31, 1471-1479. doi: 10.1016/s0038-0717(99)00051-6

Banerjee, S., Kirkby, C. A., Schmutter, D., Bissett, A., Kirkegaard, J. A., and Richardson, A. E. (2016). Network analysis reveals functional redundancy and keystone taxa amongst bacterial and fungal communities during organic matter decomposition in an arable soil. Soil Biol. Biochem. 97, 188-198. doi: 10.1016/j.soilbio.2016.03.017

Barberán, A., Bates, S. T., Casamayor, E. O., and Fierer, N. (2012). Using network analysis to explore co-occurrence patterns in soil microbial communities. ISME J. 6, 343-351. doi: 10.1038/ismej.2011.119

Benjamini, Y., and Hochberg, Y. (1995). Controlling the false discovery rate - A practical and powerful approach to multiple testing. J. R. Stat. Soc. Ser. B Stat. Methodol. 57, 289-300.

Blagodatskaya, E., and Kuzyakov, Y. (2008). Mechanisms of real and apparent priming effects and their dependence on soil microbial biomass and community structure: critical review. Biol. Fertil. Soils 45, 115-131. doi: 10.1007/s00374-008-0334-y

Calleja-Cervantes, M. E., Fernandez-Gonzalez, A. J., Irigoyen, I., FernandezLopez, M., Aparicio-Tejo, P. M., and Menendez, S. (2015). Thirteen years of continued application of composted organic wastes in a vineyard modify soil quality characteristics. Soil Biol. Biochem. 90, 241-254. doi: 10.1016/j.soilbio.2015.07.002

Caporaso, J. G., Kuczynski, J., Stombaugh, J., Bittinger, K., Bushman, F. D., Costello, E. K., et al. (2010). QIIME allows analysis of highthroughput community sequencing data. Nat. Methods 7, 335-336. doi: $10.1038 /$ nmeth.f.303

Caporaso, J. G., Lauber, C. L., Walters, W. A., Berg-Lyons, D., Lozupone, C. A., Turnbaugh, P. J., et al. (2011). Global patterns of $16 \mathrm{~S}$ rRNA diversity at a depth of millions of sequences per sample. Proc. Natl. Acad. Sci. U.S. A. 108, 4516-4522. doi: 10.1073/pnas.1000080107

Carbonetto, B., Rascovan, N., Alvarez, R., Mentaberry, A., and Vazquez, M. P. (2014). Structure, composition and metagenomic profile of soil microbiomes

\section{AUTHOR CONTRIBUTIONS}

JZ, FL, and LC designed the study. LC analyzed the data and wrote the manuscript. FL collected and analyzed soil samples. JY and SH contributed to the management and maintenance of long-term field experiment. All authors reviewed the manuscript.

\section{ACKNOWLEDGMENTS}

All authors are grateful to two reviewers and the editor for their insightful comments that improved this manuscript greatly. We thank Zhiying Guo for the help of sequence processing. This work was jointly supported by the National Key Research and Development Program of China (2016YFD0300802, 2016YFD0200107), the Strategic Pilot and Technology Special Funds of the Chinese Academy of Sciences (XDB15030302), and the National Natural Science Foundation of China (41471182).

\section{SUPPLEMENTARY MATERIAL}

The Supplementary Material for this article can be found online at: http://journal.frontiersin.org/article/10.3389/fmicb. 2017.00187/full\#supplementary-material

associated to agricultural land use and tillage systems in Argentine Pampas. PLoS ONE 9:e99949. doi: 10.1371/journal.pone.0099949

Cederlund, H., Wessen, E., Enwall, K., Jones, C. M., Juhanson, J., Pell, M., et al. (2014). Soil carbon quality and nitrogen fertilization structure bacterial communities with predictable responses of major bacterial phyla. Appl. Soil Ecol. 84, 62-68. doi: 10.1016/j.apsoil.2014.06.003

Chen, C., Zhang, J. N., Lu, M., Qin, C., Chen, Y. H., Yang, L., et al. (2016). Microbial communities of an arable soil treated for 8 years with organic and inorganic fertilizers. Biol. Fertil. Soils 52, 455-467. doi: 10.1007/s00374-0161089-5

Chen, F., Wang, H., Cao, Y. J., Li, X. Y., and Wang, G. J. (2015c). High quality draft genomic sequence of Arenimonas donghaensis DSM 18148(T). Stand. Genomic Sci. 10, 59. doi: 10.1186/s40793-015-0055-4

Chen, L., Brookes, P. C., Xu, J. M., Zhang, J. B., Zhang, C. Z., Zhou, X. Y., et al. (2016). Structural and functional differentiation of the root-associated bacterial microbiomes of perennial ryegrass. Soil Biol. Biochem. 98, 1-10. doi: 10.1016/j.soilbio.2016.04.004

Chen, L., Xu, J. M., Feng, Y. Z., Wang, J. T., Yu, Y. J., and Brookes, P. C. (2015a). Responses of soil microeukaryotic communities to short-term fumigationincubation revealed by MiSeq amplicon sequencing. Front. Microbiol. 6:1149. doi: 10.3389/fmicb.2015.01149

Chen, L., Zhang, J. B., Zhao, B. Z., Zhou, G. X., and Ruan, L. (2015b). Bacterial community structure in maize stubble-amended soils with different moisture levels estimated by bar-coded pyrosequencing. Appl. Soil Ecol. 86, 62-70. doi: 10.1016/j.apsoil.2014.09.011

Chu, H. Y., Lin, X. G., Fujii, T., Morimoto, S., Yagi, K., Hu, J. L., et al. (2007). Soil microbial biomass, dehydrogenase activity, bacterial community structure in response to long-term fertilizer management. Soil Biol. Biochem. 39, 2971-2976. doi: 10.1016/j.soilbio.2007.05.031

Cole, J. R., Wang, Q., Fish, J. A., Chai, B. L., McGarrell, D. M., Sun, Y. N., et al. (2014). Ribosomal Database Project: data and tools for high throughput rRNA analysis. Nucleic Acids Res. 42, D633-D642. doi: 10.1093/nar/gkt1244

Davidson, E. A. (2009). The contribution of manure and fertilizer nitrogen to atmospheric nitrous oxide since 1860. Nat. Geosci. 2, 659-662. doi: $10.1038 /$ ngeo608 
Demoling, F., Figueroa, D., and Bååth, E. (2007). Comparison of factors limiting bacterial growth in different soils. Soil Biol. Biochem. 39, 2485-2495. doi: 10.1016/j.soilbio.2007.05.002

Ding, J. L., Jiang, X., Ma, M. C., Zhou, B. K., Guan, D. W., Zhao, B. S., et al. (2016). Effect of 35 years inorganic fertilizer and manure amendment on structure of bacterial and archaeal communities in black soil of northeast China. Appl. Soil Ecol. 105, 187-195. doi: 10.1016/j.apsoil.2016.04.010

Edgar, R. C. (2010). Search and clustering orders of magnitude faster than BLAST. Bioinformatics 26, 2460-2461. doi: 10.1093/bioinformatics/btq461

Edgar, R. C. (2013). UPARSE: highly accurate OTU sequences from microbial amplicon reads. Nat. Methods 10, 996-998. doi: 10.1038/nmeth.2604

Eilers, K. G., Lauber, C. L., Knight, R., and Fierer, N. (2010). Shifts in bacterial community structure associated with inputs of low molecular weight carbon compounds to soil. Soil Biol. Biochem. 42, 896-903. doi: 10.1016/j.soilbio.2010.02.003

Fierer, N., Bradford, M. A., and Jackson, R. B. (2007). Toward an ecological classification of soil bacteria. Ecology 88, 1354-1364. doi: 10.1890/05-1839

Fierer, N., Ladau, J., Clemente, J. C., Leff, J. W., Owens, S. M., Pollard, K. S., et al. (2013). Reconstructing the microbial diversity and function of preagricultural tallgrass prairie soils in the United States. Science 342, 621-624. doi: $10.1126 /$ science. 1243768

Folman, L. B., Gunnewiek, P., Boddy, L., and de Boer, W. (2008). Impact of white-rot fungi on numbers and community composition of bacteria colonizing beech wood from forest soil. FEMS Microbiol. Ecol. 63, 181-191. doi: 10.1111/j.1574-6941.2007.00425.x

Francioli, D., Schulz, E., Lentendu, G., Wubet, T., Buscot, F., and Reitz, T. (2016). Mineral vs. organic amendments: microbial community structure, activity and abundance of agriculturally relevant microbes are driven by long-term fertilization strategies. Front. Microbiol. 7:1446. doi: 10.3389/fmicb.2016.01446

Fuhrman, J. A. (2009). Microbial community structure and its functional implications. Nature 459, 193-199. doi: 10.1038/nature08058

Gong, W., Yan, X. Y., Wang, J. Y., Hu, T. X., and Gong, Y. B. (2009). Long-term manure and fertilizer effects on soil organic matter fractions and microbes under a wheat-maize cropping system in northern China. Geoderma 149, 318-324. doi: 10.1016/j.geoderma.2008.12.010

Helgason, B. L., Walley, F. L., and Germida, J. J. (2010). Long-term notill management affects microbial biomass but not community composition in Canadian prairie agroecosytems. Soil Biol. Biochem. 42, 2192-2202. doi: 10.1016/j.soilbio.2010.08.015

Hervé, V., Le Roux, X., Uroz, S., Gelhaye, E., and Frey-Klett, P. (2014). Diversity and structure of bacterial communities associated with Phanerochaete chrysosporium during wood decay. Environ. Microbiol. 16, 2238-2252. doi: 10.1111/1462-2920.12347

Huy, H., Jin, L., Lee, Y. K., Lee, K. C., Lee, J. S., Yoon, J. H., et al. (2013). Arenimonas daechungensis sp nov., isolated from the sediment of a eutrophic reservoir. Int. J. Syst. Evol. Microbiol. 63, 484-489. doi: 10.1099/ijs.0.035410-0

Jin, L., Kim, K. K., An, K. G., Oh, H. M., and Lee, S. T. (2012). Arenimonas daejeonensis sp nov., isolated from compost. Int. J. Syst. Evol. Microbiol. 62, 1674-1678. doi: 10.1099/ijs.0.034868-0

Lazcano, C., Gomez-Brandon, M., Revilla, P., and Dominguez, J. (2013). Short-term effects of organic and inorganic fertilizers on soil microbial community structure and function. Biol. Fertil. Soils 49, 723-733. doi: 10.1007/s00374-012-0761-7

Lentendu, G., Wubet, T., Chatzinotas, A., Wilhelm, C., Buscot, F., and Schlegel, M. (2014). Effects of long-term differential fertilization on eukaryotic microbial communities in an arable soil: a multiple barcoding approach. Mol. Ecol. 23, 3341-3355. doi: 10.1111/mec.12819

Liu, E. K., Yan, C. R., Mei, X. R., He, W. Q., Bing, S. H., Ding, L. P., et al. (2010). Long-term effect of chemical fertilizer, straw, and manure on soil chemical and biological properties in northwest China. Geoderma 158, 173-180. doi: 10.1016/j.geoderma.2010.04.029

Liu, J. J., Sui, Y. Y., Yu, Z. H., Shi, Y., Chu, H. Y., Jin, J., et al. (2014). High throughput sequencing analysis of biogeographical distribution of bacterial communities in the black soils of northeast China. Soil Biol. Biochem. 70, 113-122. doi: 10.1016/j.soilbio.2013.12.014

Love, M. I., Huber, W., and Anders, S. (2014). Moderated estimation of fold change and dispersion for RNA-seq data with DESeq2. Genome Biol. 15:550. doi: 10.1186/s13059-014-0550-8
Lozupone, C., and Knight, R. (2005). UniFrac: a new phylogenetic method for comparing microbial communities. Appl. Environ. Microbiol. 71, 8228-8235. doi: 10.1128/AEM.71.12.8228-8235.2005

Lueders, T., Kindler, R., Miltner, A., Friedrich, M. W., and Kaestner, M. (2006). Identification of bacterial micropredators distinctively active in a soil microbial food web. Appl. Environ. Microbiol. 72, 5342-5348. doi: 10.1128/aem.00 400-06

Makk, J., Homonnay, Z. G., Keki, Z., Nemes-Barnas, K., Marialigeti, K., Schumann, P., et al. (2015). Arenimonas subflava sp nov., isolated from a drinking water network, and emended description of the genus Arenimonas. Int. J. Syst. Evol. Microbiol. 65, 1915-1921. doi: 10.1099/ijs.0.000201

Marschner, P., Kandeler, E., and Marschner, B. (2003). Structure and function of the soil microbial community in a long-term fertilizer experiment. Soil Biol. Biochem. 35, 453-461. doi: 10.1016/s0038-0717(02)00297-3

Nemergut, D. R., Cleveland, C. C., Wieder, W. R., Washenberger, C. L., and Townsend, A. R. (2010). Plot-scale manipulations of organic matter inputs to soils correlate with shifts in microbial community composition in a lowland tropical rain forest. Soil Biol. Biochem. 42, 2153-2160. doi: 10.1016/j.soilbio.2010.08.011

Pascault, N., Ranjard, L., Kaisermann, A., Bachar, D., Christen, R., Terrat, S., et al. (2013). Stimulation of different functional groups of bacteria by various plant residues as a driver of soil priming effect. Ecosystems 16, 810-822. doi: 10.1007/s10021-013-9650-7

Philippot, L., Andersson, S. G. E., Battin, T. J., Prosser, J. I., Schimel, J. P., Whitman, W. B., et al. (2010). The ecological coherence of high bacterial taxonomic ranks. Nat. Rev. Microbiol. 8, 523-529. doi: 10.1038/nrmicro2367

Rawat, S. R., Mannisto, M. K., Bromberg, Y., and Haggblom, M. M. (2012). Comparative genomic and physiological analysis provides insights into the role of Acidobacteria in organic carbon utilization in Arctic tundra soils. FEMS Microbiol. Ecol. 82, 341-355. doi: 10.1111/j.1574-6941.2012.01381.x

Reshef, D. N., Reshef, Y. A., Finucane, H. K., Grossman, S. R., McVean, G., Turnbaugh, P. J., et al. (2011). Detecting novel associations in large data sets. Science 334, 1518-1524. doi: 10.1126/science. 1205438

Seufert, V., Ramankutty, N., and Foley, J. A. (2012). Comparing the yields of organic and conventional agriculture. Nature 485, 229-232. doi: $10.1038 /$ nature 11069

Shanks, O. C., Kelty, C. A., Archibeque, S., Jenkins, M., Newton, R. J., McLellan, S. L., et al. (2011). Community structures of fecal bacteria in cattle from different animal feeding operations. Appl. Environ. Microbiol. 77, 2992-3001. doi: 10.1128/aem.02988-10

Shannon, P., Markiel, A., Ozier, O., Baliga, N. S., Wang, J. T., Ramage, D., et al. (2003). Cytoscape: a software environment for integrated models of biomolecular interaction networks. Genome Res. 13, 2498-2504. doi: 10.1101/gr.1239303

Shen, J. P., Zhang, L. M., Guo, J. F., Ray, J. L., and He, J. Z. (2010). Impact of long-term fertilization practices on the abundance and composition of soil bacterial communities in Northeast China. Appl. Soil Ecol. 46, 119-124. doi: 10.1016/j.apsoil.2010.06.015

Shi, S. J., Richardson, A. E., O'Callaghan, M., DeAngelis, K. M., Jones, E. E., Stewart, A., et al. (2011). Effects of selected root exudate components on soil bacterial communities. FEMS Microbiol. Ecol. 77, 600-610. doi: 10.1111/j.1574-6941.2011.01150.x

Su, J. Q., Ding, L. J., Xue, K., Yao, H. Y., Quensen, J., Bai, S. J., et al. (2015). Longterm balanced fertilization increases the soil microbial functional diversity in a phosphorus-limited paddy soil. Mol. Ecol. 24, 136-150. doi: 10.1111/mec. 13010

Sul, W. J., Asuming-Brempong, S., Wang, Q., Tourlousse, D. M., Penton, C. R., Deng, Y., et al. (2013). Tropical agricultural land management influences on soil microbial communities through its effect on soil organic carbon. Soil Biol. Biochem. 65, 33-38. doi: 10.1016/j.soilbio.2013.05.007

Sun, R. B., Zhang, X. X., Guo, X. S., Wang, D. Z., and Chu, H. Y. (2015). Bacterial diversity in soils subjected to long-term chemical fertilization can be more stably maintained with the addition of livestock manure than wheat straw. Soil Biol. Biochem. 88, 9-18. doi: 10.1016/j.soilbio.2015.05.007

Tabatabai, M. A. (1994). "Soil enzymes," in: Methods of Soil Analysis. Part 2. Microbiological and Biochemical Properties, eds R. W. Weaver, S. Angle, P. Bottomley, D. Bezdicek, S. Smith, and M. A. Tabatabai et al. (Madison, WI: Soil Science Society of America), 775-833. 
Tveit, A. T., Urich, T., and Svenning, M. M. (2014). Metatranscriptomic analysis of Arctic peat soil microbiota. Appl. Environ. Microbiol. 80, 5761-5772. doi: 10.1128/aem.01030-14

Vick-Majors, T. J., Priscu, J. C., and Amaral-Zettler, L. A. (2014). Modular community structure suggests metabolic plasticity during the transition to polar night in ice-covered Antarctic lakes. ISME J. 8, 778-789. doi: 10.1038/ismej.2013.190

Wang, W. H., Wang, H., Feng, Y. Z., Wang, L., Xiao, X. J., Xi, Y. G., et al. (2016). Consistent responses of the microbial community structure to organic farming along the middle and lower reaches of the Yangtze River. Sci. Rep. 6:35046. doi: 10.1038/srep35046

Wardle, D. A., Yeates, G. W., Nicholson, K. S., Bonner, K. I., and Watson, R. N. (1999). Response of soil microbial biomass dynamics, activity and plant litter decomposition to agricultural intensification over a seven-year period. Soil Biol. Biochem. 31, 1707-1720. doi: 10.1016/s0038-0717(99)00090-5

Wei, W. L., Yan, Y., Cao, J., Christie, P., Zhang, F. S., and Fan, M. S. (2016). Effects of combined application of organic amendments and fertilizers on crop yield and soil organic matter: an integrated analysis of long-term experiments. Agr. Ecosyst. Environ. 225, 86-92. doi: 10.1016/j.agee.2016.04.004

Whitman, T., Pepe-Ranney, C., Enders, A., Koechli, C., Campbell, A., Buckley, D. H., et al. (2016). Dynamics of microbial community composition and soil organic carbon mineralization in soil following addition of pyrogenic and fresh organic matter. ISME J. 10, 2918-2930. doi: 10.1038/ismej.2016.68

Williams, A., Borjesson, G., and Hedlund, K. (2013). The effects of 55 years of different inorganic fertiliser regimes on soil properties and microbial community composition. Soil Biol. Biochem. 67, 41-46. doi: 10.1016/j.soilbio.2013.08.008

Xu, H. J., Wang, X. H., Li, H., Yao, H. Y., Su, J. Q., and Zhu, Y. G. (2014). Biochar impacts soil microbial community composition and nitrogen cycling in an acidic soil planted with rape. Environ. Sci. Technol. 48, 9391-9399. doi: $10.1021 /$ es5021058

Yin, C. T., Hulbert, S. H., Schroeder, K. L., Mavrodi, O., Mavrodi, D., Dhingra, A., et al. (2013). Role of bacterial communities in the natural suppression of
Rhizoctonia solani bare patch disease of wheat (Triticum aestivum L.). Appl. Environ. Microbiol. 79, 7428-7438. doi: 10.1128/aem.01610-13

Zhang, H., Sekiguchi, Y., Hanada, S., Hugenholtz, P., Kim, H., Kamagata, Y., et al. (2003). Gemmatimonas aurantiaca gen. nov., sp nov., a gram-negative, aerobic, polyphosphate-accumulating micro-organism, the first cultured representative of the new bacterial phylum Gemmatimonadetes phyl. nov. Int. J. Syst. Evol. Microbiol. 53, 1155-1163. doi: 10.1099/ijs.0.02520-0

Zhong, W. H., Gu, T., Wang, W., Zhang, B., Lin, X. G., Huang, Q. R., et al. (2010). The effects of mineral fertilizer and organic manure on soil microbial community and diversity. Plant Soil 326, 511-522. doi: 10.1007/s11104-009-9988-y

Zhong, Y. Q., Yan, W. M., and Shangguan, Z. (2015). Impact of long-term $\mathrm{N}$ additions upon coupling between soil microbial community structure and activity, and nutrient-use efficiencies. Soil Biol. Biochem. 91, 151-159. doi: 10.1016/j.soilbio.2015.08.030

Zhou, J., Guan, D. W., Zhou, B. K., Zhao, B. S., Ma, M. C., Qin, J., et al. (2015). Influence of 34-years of fertilization on bacterial communities in an intensively cultivated black soil in northeast China. Soil Biol. Biochem. 90, 42-51. doi: 10.1016/j.soilbio.2015.07.005

Zhou, X. W., Li, S. G., Li, W., Jiang, D. M., Han, K., Wu, Z. H., et al. (2014). Myxobacterial community is a predominant and highly diverse bacterial group in soil niches. Environ. Microbiol. Rep. 6, 45-56. doi: 10.1111/1758-2229.12107

Conflict of Interest Statement: The authors declare that the research was conducted in the absence of any commercial or financial relationships that could be construed as a potential conflict of interest.

Copyright (C) 2017 Li, Chen, Zhang, Yin and Huang. This is an open-access article distributed under the terms of the Creative Commons Attribution License (CC BY). The use, distribution or reproduction in other forums is permitted, provided the original author(s) or licensor are credited and that the original publication in this journal is cited, in accordance with accepted academic practice. No use, distribution or reproduction is permitted which does not comply with these terms. 